\title{
Recent breast cancer incidence trends according to hormone therapy use: the California Teachers Study cohort
}

\author{
Sarah F Marshall ${ }^{1 *}$, Christina A Clarke ${ }^{2,3}$, Dennis Deapen ${ }^{4}$, Katherine Henderson ${ }^{5}$, Joan Largent ${ }^{1}$, \\ Susan L Neuhausen ${ }^{1}$, Peggy Reynolds ${ }^{2}$, Giske Ursin ${ }^{4,6}$, Pamela L Horn-Ross ${ }^{2}$, Daniel O Stram ${ }^{4}$, Claire Templeman ${ }^{7}$, \\ Leslie Bernstein ${ }^{5}$
}

See related editorial by Banks and Canfell, http://breast-cancer-research.com/content/12/1/103

\begin{abstract}
Introduction: Recent, international declines in breast cancer incidence are unprecedented, and the causes remain controversial. Few data sources can address breast cancer incidence trends according to pertinent characteristics like hormone therapy use history.

Methods: We used the prospective California Teachers Study to evaluate changes in self-reported use of menopausal hormone therapy (HT) between 1995 to 1996 and 2005 to 2006 and age-adjusted breast cancer incidence among 74,647 participants aged 50 years or older. Breast cancer occurrence was determined by linkage with the California Cancer Registry.

Results: During 517,286 woman years of follow up, 565 in situ and 2,668 invasive breast cancers were diagnosed. In situ breast cancer incidence rates in this population did not change significantly from 2000 to 2002 to 2003 to 2005, whereas rates of invasive breast cancer declined significantly by $26.0 \%$ from 528.0 ( $95 \%$ confidence intervals $(C l)=491.1,564.9)$ per 100,000 women in 2000 to 2002 to $390.6(95 \% \mathrm{Cl}=355.6,425.7)$ in 2003 to 2005. The decline in invasive breast cancer incidence rates was restricted to estrogen receptor-positive tumors. In 1996 to 1999 and 2000 to 2002 invasive breast cancer incidence was higher for women who reported current HT use especially estrogen-progestin (EP) use at baseline than for never or past users; but by 2003 to 2005 rates were comparable between these groups. For women who were taking EP in 2001 to 2002,75\% of whom had stopped use by 2005 to 2006, incidence had declined 30.6\% by 2003 to $2005(P=0.001)$; whereas incidence did not change significantly for those who never took HT ( $P=0.33)$.

Conclusions: Few data resources can examine prospectively individual HT use and breast cancer diagnosis. Stable in situ breast cancer rates imply consistent levels of screening and suggest recent declines in invasive breast cancer to be explained predominantly by changes in HT use.
\end{abstract}

\section{Introduction}

Several reports document recent declines in the incidence of invasive breast cancer in the US [1-7] and throughout developed countries [8-13]. The reasons for and timing of these declines is controversial. Most researchers have suggested that the sharp decline

\footnotetext{
* Correspondence: smarsha1@uci.edu

'Department of Epidemiology, School of Medicine, University of California, Irvine, 224 Irvine Hall, Irvine, CA 92697, USA
}

observed in 2002 followed widespread reductions in prescribing [14] and use of menopausal hormone therapy (HT) [15], after the July 2002 media coverage of the early termination of the Women's Health Initiative trial of estrogen-progestin (EP) therapy [16]. However, others have argued that changes in mammography use are more likely to be responsible, because subtle declines in breast cancer incidence began in 1999, predating publication of the Women's Health Initiative trial results, and because of the uncertain biological plausibility of an
C Biomed Central

(C) 2010 Marshall et al.; licensee BioMed Central Ltd. This is an open access article distributed under the terms of the Creative Commons Attribution License (http://creativecommons.org/licenses/by/2.0), which permits unrestricted use, distribution, and reproduction in any medium, provided the original work is properly cited. 
instantaneous change in risk after HT cessation [5]. A sharp decrease in breast cancer incidence in 2002 was reported by at least one cohort defined by regular mammography use [4], but thus far, data documenting incidence trends among women according to their personal HT use are very limited. The ongoing California Teachers Study (CTS) cohort has collected information on participants' HT use periodically since 1995-1996 and is a population with high rates of mammographic screening and HT use [17]. Capitalizing on the capacity to examine long-term trends according to personal HT use history in the CTS, we evaluated changes in breast cancer occurrence over the period from 1996-2005.

\section{Materials and methods}

The CTS, a cohort of female public school teachers and administrators, was established in 1995-1996 to study breast cancer and other women's health issues [17]. The study protocol was approved by the institutional review boards of participating institutions. Participants reported their menopausal status and HT use on the baseline questionnaire. Information on HT use was updated in 2000-2001. This analysis of incidence rates of breast cancer was limited to women who were California residents at baseline and who had no history of in situ or invasive breast cancer $(\mathrm{n}=118,261)$. Women who were premenopausal $(\mathrm{n}=12,908)$, had missing data on HT use at baseline or in the 2000-2001 follow-up questionnaire $(\mathrm{n}=3222)$, or did not achieve the age of 50 years ( $n=27,484)$ during the course of the follow-up period (1995-2005) were ineligible for the analyses. As hormones may be taken during the menopausal transition [15], we included women who were either perimenopausal (defined as women who reported that their menstrual periods had stopped within the past six months), postmenopausal (defined as women who reported that their menstrual periods had stopped more than six months ago), or those whose menopausal status was unknown because they were taking HT. As women who were aged 40-49 years at baseline turned 50 years during the follow-up period, they were entered into the analyses. A total of 74,647 women were included in the analyses. HT use was categorized as 'never', 'past', or 'current' in 1995-1996 according to the baseline questionnaire and during follow up in 2000-2001 according to the third questionnaire. For descriptive purposes only, we evaluated how many women had stopped or started HT by the end of follow up in 2005, by examining HT use among 44,108 women who additionally answered HT questions on the 2005-2006 questionnaire. This information is used to illustrate changes in HT use that occurred after 2000-2001; however, the small number of breast cancers that occurred in the interval between 2000-2001 and 2005-2006 precluded subgroup analyses. Informed consent of participants was implied by questionnaire completion.

Incident diagnoses of invasive and in situ breast cancer (International Classification of Diseases for Oncology, Third Edition (ICD-O-3) site codes 500-509, excluding morphology codes 9590-9989) were identified by annual linkage with the California Cancer Registry [18]. Cancer data were complete through to 31 December, 2005. The cohort was followed from the date of completion of the baseline questionnaire until the earliest of the following events: the date of first in situ or invasive breast cancer diagnosis, date of death, date of move outside of California, or 31 December, 2005. Continued California residence was self reported on three follow-up questionnaires and was supplemented by the information obtained from the US Postal Service National Change of Address database and change of address cards provided in the annual newsletter that were submitted by participants. Deaths were identified through annual probabilistic record linkage to the California state mortality file, the national Social Security Administration death master file and the National Death Index. Women who moved out of state or died during a calendar year contributed woman months of follow up until the month of move or death. Woman years, as the denominators for incidence rates for each period of analysis, were accrued based on the above described eligibility criteria and are shown in Table 1. We used SAS version 9.2 (SAS Institute, Cary, NC, USA) to calculate age-adjusted incidence rates per 100,000 woman years, standardized to the 2000 US population (10 age groups - Census P25-1130), and corresponding 95\% confidence intervals (CI) for three distinct time periods; 1996-1999, 2000-2002, and 20032005 , a) for invasive breast cancer overall, and by estrogen receptor (ER) status and for in situ breast cancer, b) according to HT use reported at baseline, and c) according to HT use reported in 2000-2001. We did not have adequate numbers of cases to conduct regression-based assessments of trends, thus we calculated 95\% CI and tested whether the changes between time period-specific rates were statistically significant, treating 2000-2002 as the reference group, using a z score [19]. Where multiple time periods were assessed the $P$ values were adjusted for multiple comparisons using a Bonferroni correction [20].

All analyses were repeated to determine the influence of including a small number of women who reported on the baseline questionnaire that they did not receive regular screening for breast cancer. Observed trends were essentially unchanged whether including or excluding these unscreened women. Therefore, we present below results including all women regardless of the regularity of their mammographic screening. 
Table 1 Age-standardized baseline characteristics of menopausal women in the California Teachers Study according to hormone therapy (HT) use in 1995-1996

\begin{tabular}{lcccc}
\hline & $\begin{array}{c}\text { Never HT } \\
(\mathbf{n = 1 4 , 0 7 0 )}\end{array}$ & $\begin{array}{c}\text { Past HT } \\
(\mathbf{n}=\mathbf{7 9 1 4})\end{array}$ & $\begin{array}{c}\text { Current E } \\
(\mathbf{n}=\mathbf{1 5 , 4 0 7})\end{array}$ & $\begin{array}{c}\text { Current EP } \\
(\mathbf{n}=\mathbf{1 6 , 9 3 4 )}\end{array}$ \\
\hline Mean age in years & 66.5 & 68.2 & 63.3 & 58.9 \\
\% Non-Hispanic white & 85.3 & 87.9 & 90.1 & 92.2 \\
\% First-degree family history of breast cancer & 15.2 & 14.9 & 13.2 & 12.2 \\
\% BMl overweight or obese $\geq 25 \mathrm{~kg} / \mathrm{m}^{2}$ & 45.2 & 45.2 & 41.6 & 34.9 \\
\% High alcohol intake (average $\geq 20 \mathrm{~g} /$ day) & 8.6 & 9.3 & 9.5 & 10.4 \\
\% Highest quartile of residential socioeconomic status & 44.4 & 44.8 & 47.5 & 52.5 \\
\% Menarche at age 11 years or younger & 22.0 & 23.4 & 23.6 & 20.9 \\
\% Nulliparous & 23.5 & 19.5 & 18.8 & 7.5 \\
\% Parous before age 35 years & 70.2 & 74.8 & 76.3 & 75.1 \\
\hline
\end{tabular}

$\mathrm{BMI}=$ body mass index; $\mathrm{E}=$ estrogen only; $\mathrm{EP}$ = estrogen and progestin combined therapy.

Age-standardized by 10-year age categories to the age distribution of menopausal women in analysis.

\section{Results}

During 517,286 woman years of follow up, 566 in situ and 2668 invasive breast cancers were diagnosed. Among the invasive tumors, 1945 (72.9\%) were ER positive; 324 (12.1\%) were ER negative; and 399 (15.0\%) were borderline or ER status was unknown (Table 1). At baseline, $26.5 \%$ of age-eligible participants had never taken HT, $59.9 \%$ were current users and $13.5 \%$ were past users. In 2000-2001, with an additional 5599 women having aged into the analysis cohort, $23.0 \%$ were classified as never HT users, $57.7 \%$ were current users and $19.3 \%$ were past users. By $2005-2006,26.9 \%$ had never taken HT, $21.0 \%$ reported current use and 52.1\% were past users. By the end of follow up in 2005-2006, $75.0 \%$ of those reporting current EP use in 2000-2001, and $55.8 \%$ of those reporting current estrogen-only HT use, had stopped HT use.

\section{Baseline characteristics according to HT use history}

Compared with women who had never taken HT, current users were more likely to be younger and non-Hispanic white (Table 1). Current EP users were more likely than estrogen-only HT users, or past or never HT users to live in an area with the highest socioeconomic status and were much less likely to be overweight or obese. Women who had never taken HT were less likely to have had their first full-term pregnancy before age 35 years. Family history of breast cancer, age at menarche and alcohol intake did not differ by HT use history.

\section{Breast cancer incidence rates}

Overall, age-adjusted incidence rates of in situ breast cancer did not change substantially (change from 19961999 to $2000-2002, P=0.09$; from $2000-2002$ to 2003 $2005, P=0.24$; Figure 1). However, incidence rates of invasive breast cancer peaked in 2000-2002, and then declined by $26.0 \%$ from $528.0(95 \% \mathrm{CI}=491.1$ to 564.9 ) per 100,000 women in $2000-2002$ to $390.6(95 \% \mathrm{CI}=$
355.6 to 425.7$)$ per 100,000 woman years in 2003-2005 (Table 2). The decline in rates from 2000-2002 to 20032005 was statistically significant $(P<0.001)$. Examining trends separately by ER status, declines were limited to ER-positive cancer, for which rates peaked in 2000-2002 at 390.6 per 100,000 woman years before declining $24.8 \%$ to 293.8 in $2003-2005(P<0.001)$. Rates of ERnegative cancer were generally stable throughout the time period; the slight $14.1 \%$ decline in rates between 2000-2002 and 2003-2005 was not statistically significant $(P=0.38)$. Among women with invasive breast cancer, $77.8 \%$ with ER-positive disease and $70.4 \%$ with ER-negative disease reported having used HT at some time on their baseline questionnaire.

\section{Incidence rates by HT use history}

Figure 2 shows invasive and in situ breast cancer incidence trends according to HT use reported on the baseline questionnaire. Women who reported currently taking EP at baseline had consistently higher rates of invasive and in situ breast cancer than estrogen-only HT users or never or past HT users. Whereas the ageadjusted incidence rates of invasive breast cancer between 2000-2002 and 2003-2005 were stable for never users and past users of HT, among women who reported current use of EP at baseline, incidence rates declined significantly by $45.8 \%$ from 782.7 (95\% CI = 687.1 to 878.2 ) per 100,000 in $2000-2002$ to 424.6 (95\% $\mathrm{CI}=353.5$ to 495.7$)$ in 2003-2005 $(P<0.001$; Table 3$)$. Women currently taking EP also experienced the largest decline in rates of in situ cancer (percent change = -46.7, $P=0.008$ ). Declines in breast cancer rates among current $\mathrm{E}$ users were also observed (invasive percent change $=-26.1 \%, P=0.010$; in situ percent change $=$ $-23.3 \%, P=0.23$ ).

HT use was reassessed on a second questionnaire administered in 2000. Breast cancer incidence was calculated for two time periods 2001-2002 and 2003-2005 


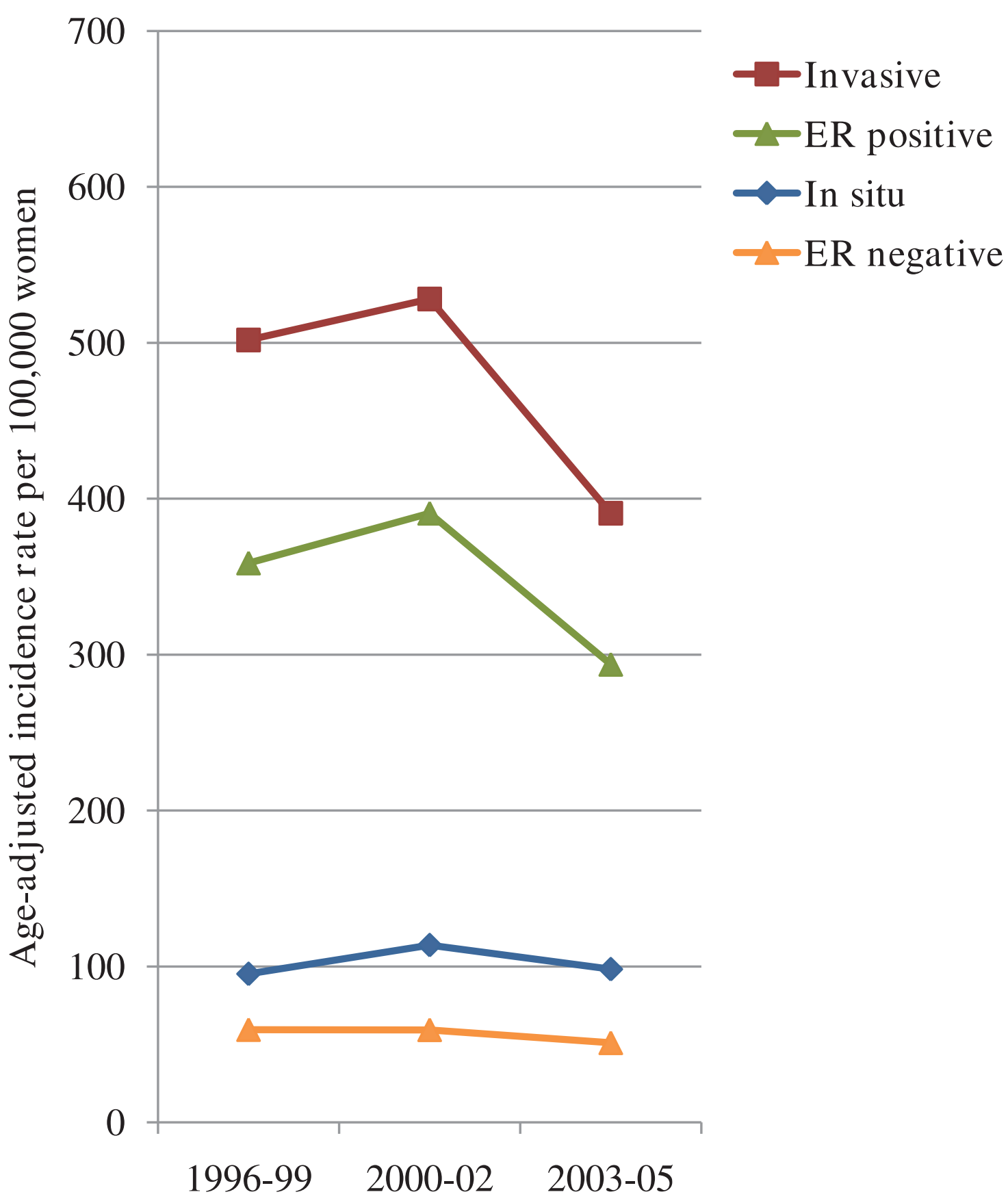

Figure 1 Age-adjusted incidence rates of breast cancer according to type of tumor and estrogen receptor (ER) status of invasive cancers among menopausal women $\mathbf{5 0}$ years or older in the California Teachers Study.

classified according to participants' HT use reported for 2000-2001. Figure 3 and Table 4 show that during this time, invasive and in situ breast cancer rates declined for all categories of HT users, except for women who had never taken HT, in whom there was a non-significant increase of $23.8 \%$ in in situ breast cancer between the two time periods. Age-adjusted incidence rates for invasive breast cancer declined rapidly for women who had stopped HT by 2000-2001 ('past HT use') from $561.1(95 \% \mathrm{CI}=432.4$ to 689.8 ) per 100,000 women in 2001-2002 to $340.0(95 \% \mathrm{CI}=265.6$ to 414.4$)$ per 100,000 in $2003-2005$, an overall decline of $39.4 \%(P=$ 0.003). A similar decline was observed for women who were current users of EP in 2000-2001 (percent change = $-30.6, P=0.001$ ), and to a lesser extent, for current estrogen-only HT users (percent change $=-24.0, P=0.030$ ). 
Table 2 Age-adjusted incidence rate (AAIR) of breast cancer, according to type of tumor and estrogen receptor (ER) status of invasive cancers among menopausal women in the California Teachers Study

\begin{tabular}{|c|c|c|c|c|c|c|c|c|c|}
\hline \multirow[t]{2}{*}{ Period } & \multirow{2}{*}{$\begin{array}{c}\text { Woman } \\
\text { years }\end{array}$} & \multicolumn{2}{|r|}{ In situ } & \multicolumn{2}{|r|}{ Invasive } & \multicolumn{2}{|r|}{ ER positive } & \multicolumn{2}{|c|}{ ER negative } \\
\hline & & $\mathrm{n}$ & AAIR (95\% CI) & $\mathrm{n}$ & AAIR $(95 \% \mathrm{Cl})$ & $\mathrm{n}$ & AAIR $(95 \% \mathrm{Cl})$ & $n$ & AAIR $(95 \% \mathrm{CI})$ \\
\hline 1996-99 & 208,860 & 207 & $95.2(81.6-108.7)$ & 1072 & $501.7(470.3-533.1)$ & 765 & $358.7(332.1-385.3)$ & 127 & $59.5(48.6-70.3)$ \\
\hline $2000-02$ & 158,917 & 197 & $113.7(96.5-130.9)$ & 914 & $528.0(491.1-564.9)$ & 676 & $390.6(358.8-422.3)$ & 103 & $59.4(46.9-71.9)$ \\
\hline 2003-05 & 149,509 & 161 & $98.2(79.1-117.3)$ & 682 & $390.6(355.6-425.7)$ & 504 & $293.8(261.9-325.7)$ & 94 & $51.0(40.5-61.5)$ \\
\hline Total cases & & 565 & & 2668 & & 1945 & & 324 & \\
\hline $\begin{array}{l}\% \text { change } \\
1996-99 \text { to 2000-02 }\end{array}$ & & & $19.4 \% P=0.09$ & & $5.2 \% P=0.30$ & & $8.9 \% P=0.13$ & & $-0.2 \% P=0.99$ \\
\hline $\begin{array}{l}\text { \% change } \\
2000-02 \text { to } 2003-05\end{array}$ & & & $-13.6 \% P=0.24$ & & $-26.0 \% P<0.001$ & & $-24.8 \% P<0.001$ & & $-14.1 \% P=0.38$ \\
\hline
\end{tabular}

$\mathrm{Cl}=$ confidence interval.

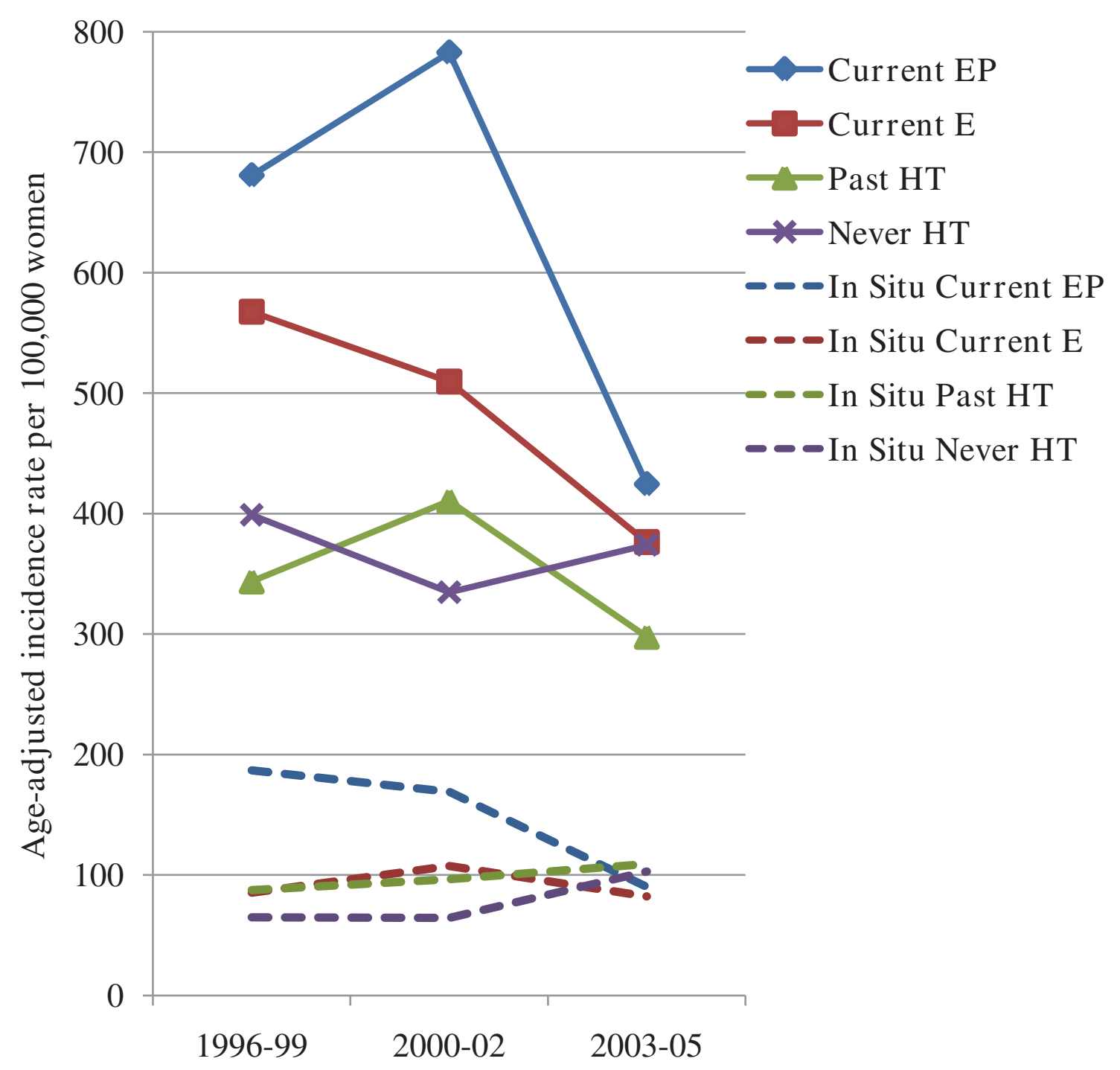

Figure 2 Age-adjusted incidence rates of invasive (solid lines) and in situ (dashed lines) breast cancer according to hormone therapy use at baseline in 1995-1996 among menopausal women 50 years or older in the California Teachers Study. E = estrogen only hormone therapy; $E P=$ estrogen-progestin hormone therapy; $H T=$ Hormone therapy. 
Table 3 Age-adjusted incidence rate (AAIR) of invasive and in situ breast cancer according to hormone therapy (HT) use at baseline in 1995-1996 among menopausal women in the California Teachers Study

\begin{tabular}{|c|c|c|c|c|}
\hline \multirow[t]{2}{*}{ Period } & Never HT & Past HT & Current E & Current EP \\
\hline & AAIR $(95 \% \mathrm{Cl})$ & AAIR $(95 \% \mathrm{Cl})$ & AAIR $(95 \% \mathrm{Cl})$ & AAIR $(95 \% \mathrm{CI})$ \\
\hline \multicolumn{5}{|c|}{ Invasive breast cancer } \\
\hline 1996-99 & $399.0(341.7-456.3)$ & $343.7(268.8-418.6)$ & $567.5(501.1-633.9)$ & $680.8(576.7-784.8)$ \\
\hline 2000-02 & 334.7 (278.5-390.9) & 410.6 (300.7-520.6) & $509.6(438.9-580.2)$ & $782.7(687.1-878.2)$ \\
\hline 2003-05 & $374.1(308.1-440.1)$ & $297.8(218.5-377.2)$ & $376.4(314.7-438.1)$ & $424.6(353.5-495.7)$ \\
\hline $\begin{array}{l}\% \text { change } \\
1996-99 \text { to 2000-02 }\end{array}$ & $-16.1 \% P=0.13$ & $19.5 \% P=0.31$ & $-10.2 \% P=0.11$ & $15.0 \% P=0.016$ \\
\hline $\begin{array}{l}\text { \% change } \\
2000-02 \text { to } 2003-05\end{array}$ & $11.8 \% P=0.38$ & $-27.5 \% P=0.17$ & $-26.1 \% P=0.010$ & $-45.8 \% P<0.001$ \\
\hline \multicolumn{5}{|c|}{ In Situ breast cancer } \\
\hline 1996-99 & $65.0(41.1-88.9)$ & $87.5(43.2-131.7)$ & $85.4(60.2-110.6)$ & $187.0(128.3-245.6)$ \\
\hline 2000-02 & $64.5(39.5-89.6)$ & $96.6(29.7-163.5)$ & 107.5 (78.1-136.9) & $169.2(128.6-209.9)$ \\
\hline 2003-05 & $103.1(60.5-145.7)$ & $131.7(163.5-160.6)$ & $82.4(56.5-108.3)$ & $90.1(65.4-114.8)$ \\
\hline $\begin{array}{l}\text { \% change } \\
1996-99 \text { to 2000-02 }\end{array}$ & $-0.8 \% P=0.98$ & $10.4 \% P=0.82$ & $25.9 \% P=0.12$ & $-9.5 \% P=0.38$ \\
\hline $\begin{array}{l}\text { \% change } \\
2000-02 \text { to 2003-05 }\end{array}$ & $59.8 \% P=0.10$ & $36.3 \% P=0.51$ & $-23.3 \% P=0.23$ & $-46.7 \% P=0.008$ \\
\hline
\end{tabular}

$\mathrm{Cl}=$ confidence interval; $\mathrm{E}=$ estrogen only; $\mathrm{EP}=$ estrogen and progestin combined therapy.

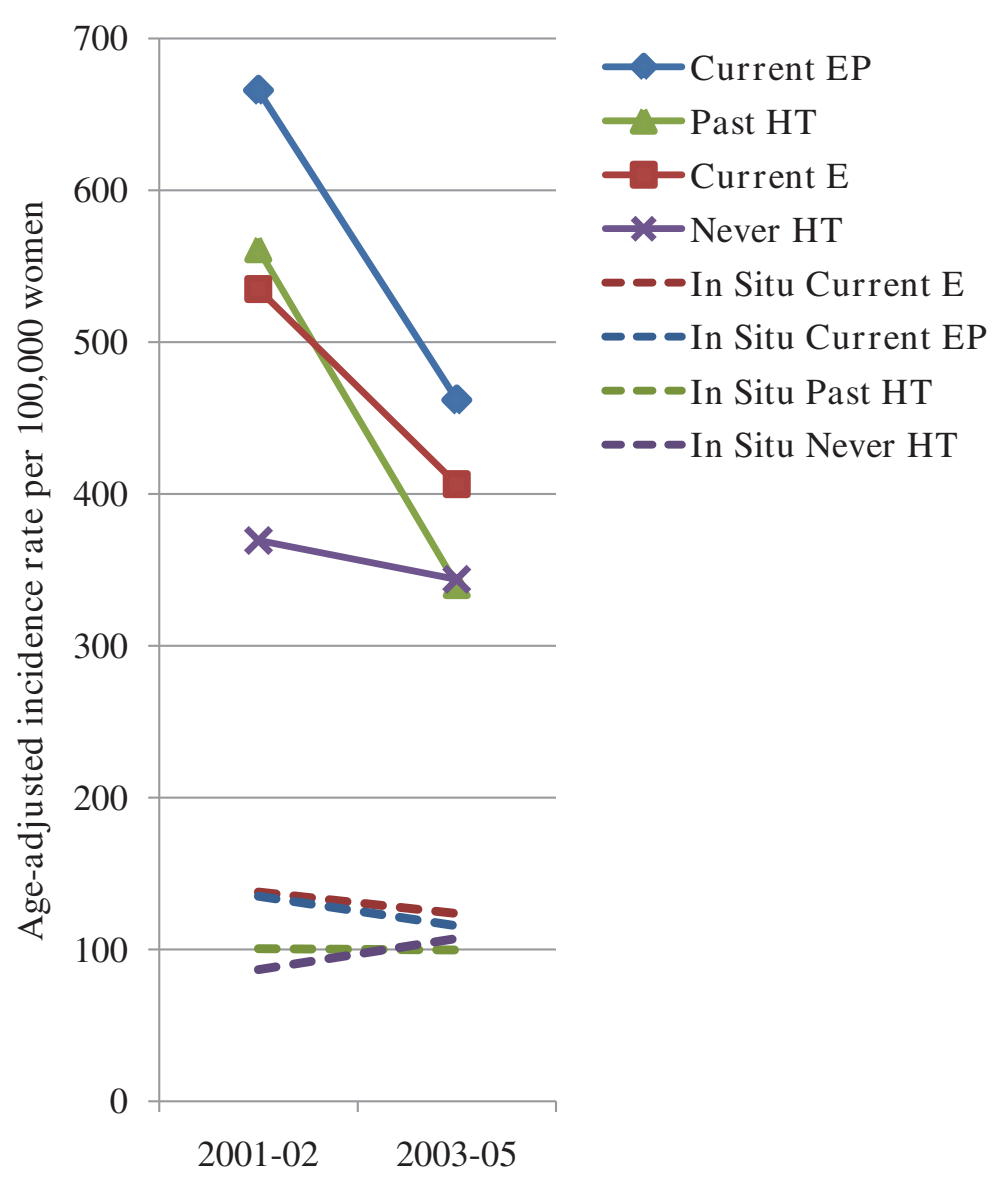

Figure 3 Age-adjusted incidence rates of invasive (solid lines) and in situ (dashed lines) breast cancer according to hormone therapy use at follow-up in 2000-2001 among menopausal women $\mathbf{5 0}$ years or older in the California Teachers Study. $E=$ estrogen only hormone therapy; $\mathrm{EP}=$ estrogen-progestin hormone therapy; $\mathrm{HT}=$ Hormone therapy. 
Table 4 Age-adjusted incidence rate (AAIR) of invasive and in situ breast cancer according to hormone therapy (HT) use at follow-up in 2000-2001 among menopausal women in the California Teachers Study

\begin{tabular}{|c|c|c|c|c|}
\hline \multirow[t]{2}{*}{ Period } & Never HT & Past HT & Current E & Current EP \\
\hline & AAIR $(95 \% \mathrm{Cl})$ & AAIR $(95 \% \mathrm{CI})$ & AAIR $(95 \% \mathrm{CI})$ & AAIR $(95 \% \mathrm{CI})$ \\
\hline \multicolumn{5}{|c|}{ Invasive breast cancer } \\
\hline 2001-02 & $369.3(285.6-452.9)$ & $561.1(432.4-689.8)$ & $534.9(424.7-645.1)$ & $665.8(565.9-765.7)$ \\
\hline 2003-05 & 343.7 (272.8-414.5) & $340.0(265.6-414.4)$ & $406.4(324.7-488.0)$ & $461.9(392.5-531.4)$ \\
\hline$\%$ change & $-6.9 \% P=0.33$ & $-39.4 \% P=0.003$ & $-24.0 \% P=0.030$ & $-30.6 \% P=0.001$ \\
\hline \multicolumn{5}{|c|}{ In Situ breast cancer } \\
\hline 2001-02 & $86.6(44.0-129.1)$ & $100.5(32.4-168.6)$ & 137.7 (83.2-192.3) & $135.0(95.2-174.9)$ \\
\hline 2003-05 & $107.2(63.1-151.3)$ & $99.5(60.3-138.8)$ & $123.6(67.3-179.9)$ & $115.5(78.1-152.8)$ \\
\hline$\%$ change & $23.8 \% P=0.26$ & $-1.0 \% P=0.49$ & $-10.2 \% P=0.35$ & $-14.4 \% P=0.22$ \\
\hline
\end{tabular}

$\mathrm{Cl}=$ confidence interval; $\mathrm{E}=$ estrogen only; $\mathrm{EP}=$ estrogen and progestin combined therapy.

For never users of HT, invasive incidence trends were stable between the two time periods 2001-2002 (percent change $=-6.9, P=0.33)$. None of the changes in rates observed for in situ breast cancer were statistically significant.

\section{Discussion}

Researchers using ecologic study designs have only been able to speculate that HT is responsible for the unprecedented decline in invasive breast cancer incidence observed in $2002[1,2,14,21]$. With the individual-level information on HT use history in our prospective cohort, we are able to show several important phenomena regarding breast cancer occurrence in this population: 1) $24.8 \%$ decline in ER-positive breast cancer occurring between 2000-2002 and 2003-2005 while ERnegative breast cancer remained stable; 2) incidence trends that varied substantially by HT use at baseline, with consistently higher rates among current HT users particularly EP users, than never users; 3) 45.8\% decline in breast cancer incidence from 2000-2002 to 2003-2005 observed among women who were current EP users in 2000-2002, the majority of whom (75.0\%) were likely to have ceased use by 2005, but not among women who had never used HT; and 4) stable rates among women who reported never having any HT use. Thus, these data provide further support for the stronger etiologic importance of current versus past HT use in breast cancer risk.

Among women reporting that they stopped using HT, rates of invasive breast cancer rapidly declined. This is demonstrated by both the trends in incidence among women who had stopped use by 2000-2001 ('past users') who had a $39.4 \%$ drop in rates and the trends in incidence among women who were still taking EP in 20002001, but who had largely stopped use by 2005-2006. Taken together, our observations demonstrate a strong and immediate influence of HT use and cessation on breast cancer occurrence [21].
The CTS population reports near uniformity with respect to screening compliance. Nearly $97 \%$ of CTS participants aged over 50 years at baseline reported being current with mammography guidelines at baseline. Stable in situ breast cancer rates and stable invasive breast cancer rates among women who had never taken HT imply consistent levels of screening throughout the study period and screening rates are particularly high for this population [17]. Furthermore, when we restricted our analyses to those $97 \%$ that were current with breast health screening at the start of our study, the results did not change, and similar declines in breast cancer incidence have been reported from populations of women screened uniformly [4]. Other researchers have even suggested increased usage of mammography [22]. Clearly, any possible influence of 'mammography saturation' or other screening effects will be smaller and more gradual than the recent rapid declines that we suggest are attributable to the dramatic changes in HT use.

We observed large declines in breast cancer incidence; up to $45.8 \%$ among current EP users. We feel that this decline can be attributed mostly or entirely to HT use for several reasons: a) this cohort reported high levels of HT use at baseline - more than $70 \%$ of menopausal women reported ever taking HT; b) this cohort experienced a large decline in HT use $-75 \%$ of the EP users had stopped taken it by 2005 and $56 \%$ of the estrogenonly HT alone users had also stopped; c) some studies report more than $66 \%$ increased risk due to HT use [23]; and d) the largest declines we observed were in groups that are plausible biologically - that is, current or recent EP users, and in ER-positive tumors. In fact the size and speed of the declines we observed make it unlikely that changes in other risk factors including reproductive history, body mass index, diet or alcohol use are attributable. Some authors [24] have postulated that the increased use of other medications such as raloxifene and tamoxifen may be partly responsible for reducing 
breast cancer incidence but prevalence of use in the CTS in 2005-2006 was very low (about 8.2\%) compared with HT.

Although our data come from one of the largest prospective cohorts tracking HT use, we still had limited statistical power to detect changes in annual breast cancer incidence, especially for disease subgroups. Like prior population-based studies, we also found that decreases in breast cancer incidence were only observed for ER-positive cancers [2-4]; however, we did not have a sufficient number of cases to examine trends of ERdefined breast cancers according to HT use, nor could we examine duration of HT use.

\section{Conclusions}

Along with other studies reaching similar conclusions $[1,2,25]$, our data provide further evidence that recent declines in invasive breast cancer incidence in the US are explained predominantly by decreased HT use.

\section{Abbreviations}

Cl: confidence intervals; CTS: California Teachers Study; ER: estrogen receptor; EP: estrogen-progestin hormone therapy; HT: Hormone therapy.

\section{Acknowledgements}

This research was supported by grant R01 CA77398 from the National Cancer Institute and contract 97-10500 from the California Breast Cancer Research Fund. The funding sources did not contribute to the design or conduct of the study, nor to the writing or submission of this manuscript. The collection of cancer incidence data used in this study was supported by the California Department of Health Services as part of the statewide cancer reporting program mandated by California Health and Safety Code Section 103885; the National Cancer Institute's Surveillance, Epidemiology and End Results Program under contract N01-PC-35136 awarded to the Northern California Cancer Center, contract N01-PC-35139 awarded to the University of Southern California, and contract N02-PC-15105 awarded to the Public Health Institute; and the Centers for Disease Control and Prevention's National Program of Cancer Registries, under agreement \#U55/CCR92193002 awarded to the Public Health Institute. The ideas and opinions expressed herein are those of the authors and endorsement by the State of California, Department of Health Services, the National Cancer Institute, and the Centers for Disease Control and Prevention or their contractors and subcontractors is not intended nor should be inferred.

The authors would like to thank the women who participated in the study and the CTS Steering Committee who are responsible for the formation and maintenance of the cohort within which this study was conducted but were not involved in the current paper: Hoda Anton-Culver, Ellen T. Chang, Rosemary Cress, Rich Pinder, Dee W. West, and Argyrios Ziogas.

\section{Author details}

${ }^{1}$ Department of Epidemiology, School of Medicine, University of California, Irvine, 224 Irvine Hall, Irvine, CA 92697, USA. ²Northern California Cancer Center, 2201 Walnut Avenue, Suite 300, Fremont, CA 94538, USA. ${ }^{3}$ Department of Health Research and Policy and Stanford Cancer Center, Stanford University School of Medicine, 875 Blake Wilbur Drive, Stanford, CA 94305, USA. ${ }^{4}$ Department of Preventive Medicine, University of Southern California Keck School of Medicine, Los Angeles, CA 90089, USA. ${ }^{5}$ Department of Cancer Etiology, Division of Population Sciences, City of Hope Comprehensive Cancer Center, 1500 East Duarte Road, Duarte, CA 91010, USA. 'Department of Nutrition, University of Oslo, PO Box 1046, Blindern, 0316 Oslo, Norway. ${ }^{7}$ Department of Obstetrics and Gynecology, University of Southern California Keck School of Medicine, Women's and Children's Hospital, 1240 N. Mission Road, Los Angeles, CA 90033, USA.

\section{Authors' contributions}

SFM carried out the statistical analysis and drafted the manuscript. CAC and LB conceived and supervised the analysis, helped to draft the manuscript, and participated in the design and coordination of the study. DD, KDH, JL, SLN, PR, GU, PLH-R, DOS, and CT participated in the design of the analysis and edited the manuscript. All authors read and approved the final manuscript.

\section{Competing interests}

CAC has served as an expert witness for plaintiff lawyers preparing hormone therapy litigation. All other authors declare that they have no competing interests.

Received: 7 July 2009 Revised: 9 November 2009

Accepted: 8 January 2010 Published: 8 January 2010

\section{References}

1. Robbins AS, Clarke CA: Regional changes in hormone therapy use and breast cancer incidence in California from 2001 to 2004. J Clin Oncol 2007, 25:3437-3439.

2. Ravdin PM, Cronin KA, Howlader N, Berg CD, Chlebowski RT, Feuer EJ, Edwards BK, Berry DA: The decrease in breast cancer incidence in 2003 in the United States. N Engl J Med 2007, 356:1670-1674.

3. Glass AG, Lacey JV, Carreon JD, Hoover RN: Breast cancer incidence, 19862006: Combined roles of menopausal hormone therapy, screening mammography, and estrogen receptor status. J Natl Cancer Inst 2007, 99:1152-1161.

4. Kerlikowske K, Miglioretti DL, Buist DSM, Walker R, Carney PA: Declines in invasive breast cancer and use of postmenopausal hormone therapy in a screening mammography population. J Natl Cancer Inst 2007, 99:1335-1339.

5. Li Cl, Daling JR: Changes in breast cancer incidence rates in the United States by histologic subtype and race/ethnicity, 1995-2004. Cancer Epidemiol Biomarkers Prev 2007, 16:2773-2780.

6. Clarke CA, Glaser SL, Uratsu CS, Selby JV, Kushi LH, Herrinton LJ: Recent declines in hormone therapy utilization and breast cancer incidence: clinical and population-based evidence. J Clin Oncol 2006, 24:e49-e50.

7. Jemal A, Ward E, Thun MJ: Recent trends in breast cancer incidence rates by age and tumor characteristics among U.S. women. Breast Cancer Res 2007, 9:R28.

8. Canfell K, Banks E, Moa AM, Beral V: Decrease in breast cancer incidence following a rapid fall in use of hormone replacement therapy in Australia. Med J Australia 2008, 188:641-644.

9. Allemand $H$, Seradour B, Weill A, Ricordeau P: Decline in breast cancer incidence in 2005 and 2006 in France: a paradoxical trend. Bull Cancer 2008, 95:11-15.

10. Katalinic A, Rawal R: Decline in breast cancer incidence after decrease in utilisation of hormone replacement therapy. Breast Cancer Res Treat 2007, 107:427-430

11. Kliewer EV, Demers AA, Nugent ZJ: A decline in breast-cancer incidence. N Engl J Med 2007, 357:509-510.

12. Johnston M: Breast cancer drop linked to fall in use of HRT. New Zealand Herald 2006http://www.nzherald.co.nz/section/story.cfm? c_id=204\&objectid=10416198.

13. Kumle M: Declining breast cancer incidence and decreased HRT use. Lancet 2008, 372:608-610.

14. Krieger N, Lowy I, Aronowitz R, Bigby J, Dickersin K, Garner E, Gaudillière JP, Hinestrosa C, Hubbard R, Johnson PA, Missmer SA, Norsigian J, Pearson C, Rosenberg CE, Rosenberg L, Rosenkrantz BG, Seaman B, Sonnenschein C, Soto AM, Thornton J, Weisz G: Hormone replacement therapy, cancer, controversies, and women's health: historical, epidemiological, biological, clinical, and advocacy perspectives. J Epidemiol Community Health 2005, 59:740-748.

15. Hersh AL, Stefanick ML, Stafford RS: National use of postmenopausal hormone therapy: Annual trends and response to recent evidence. JAMA 2004, 291:47-53.

16. Writing Group for the Women's Health Initiative Investigators: Risks and benefits of estrogen plus progestin in healthy postmenopausal women: Principal results from the Women's Health Initiative randomized controlled trial. JAMA 2002, 288:321-333. 
17. Bernstein $L$, Allen $M$, Anton-Culver $H$, Deapen $D$, Horn-Ross PL, Peel $D$, Pinder R, Reynolds P, Sullivan-Halley J, West D, Wright W, Ziogas A, Ross RK: High breast cancer incidence rates among California teachers: results from the California Teachers Study United States. Cancer Causes Control 2002, 13:625-635.

18. Marshall SF, Bernstein L, Anton-Culver H, Deapen D, Horn-Ross PL, Mohrenweiser H, Peel D, Pinder R, Purdie DM, Reynolds P, Stram D, West D, Wright WE, Ziogas A, Ross RK: Nonsteroidal anti-inflammatory drug use and breast cancer risk by stage and hormone receptor status. J Natl Cancer Inst 2005, 97:805-812.

19. Esteve J, Benhamou E, Raymond L: Statistical Methods in Cancer Research. Descriptive Epidemiology Lyon: International Agency for Research on Cancer 1994, 4.

20. Miller RG: Simultaneous Statistical Inference New York: Springer-Verlag, 2 1981.

21. Clarke CA, Glaser SL: Declines in breast cancer after the WHI: apparent impact of hormone therapy. Cancer Causes Control 2007, 18:847-852.

22. Tabár L, Duffy SW, Vitak B, Chen H, Prevost TC: The natural history of breast carcinoma. Cancer 1999, 86:449-462.

23. Beral V: Breast cancer and hormone-replacement therapy in the Million Women Study. Lancet 2003, 362:419-427.

24. Brewster DH, Sharpe KH, Clark DI, Collins J: Declining breast cancer incidence and decreased HRT use. Lancet 2009, 373:459-460.

25. Verkooijen HM, Koot VCM, Fioretta G, Heiden van der M, Schipper ME, Rapiti E, Peeters PH, Peterse JL, Bouchardy C: Hormone replacement therapy, mammography screening and changing age-specific incidence rates of breast cancer: an ecological study comparing two European populations. Breast Cancer Res Treat 2008, 107:389-395.

doi:10.1186/bcr2467

Cite this article as: Marshall et al:: Recent breast cancer incidence trends according to hormone therapy use: the California Teachers Study cohort. Breast Cancer Research 2010 12:R4.

\section{Submit your next manuscript to BioMed Central and take full advantage of:}

- Convenient online submission

- Thorough peer review

- No space constraints or color figure charges

- Immediate publication on acceptance

- Inclusion in PubMed, CAS, Scopus and Google Scholar

- Research which is freely available for redistribution

Submit your manuscript at www.biomedcentral.com/submit 